\title{
The Feasibility of High-Resolution Peripheral Quantitative Computed Tomography (HR-pQCT) in Patients with Suspected Scaphoid Fractures
}

Citation for published version (APA):

Bevers, M. S. A. M., Daniels, A. M., Wyers, C. E., van Rietbergen, B., Geusens, P. P. M. M.,

Kaarsemaker, S., Janzing, H. M. J., Hannemann, P. F. W., Poeze, M., \& van den Bergh, J. P. W. (2020). The Feasibility of High-Resolution Peripheral Quantitative Computed Tomography (HR-pQCT) in Patients with Suspected Scaphoid Fractures. Journal of Clinical Densitometry, 23(3), 432-442.

https://doi.org/10.1016/j.jocd.2019.08.003

Document status and date:

Published: 01/01/2020

DOI:

10.1016/j.jocd.2019.08.003

Document Version:

Publisher's PDF, also known as Version of record

Document license:

Taverne

Please check the document version of this publication:

- A submitted manuscript is the version of the article upon submission and before peer-review. There can be important differences between the submitted version and the official published version of record.

People interested in the research are advised to contact the author for the final version of the publication, or visit the DOI to the publisher's website.

- The final author version and the galley proof are versions of the publication after peer review.

- The final published version features the final layout of the paper including the volume, issue and page numbers.

Link to publication

\footnotetext{
General rights rights.

- You may freely distribute the URL identifying the publication in the public portal. please follow below link for the End User Agreement:

www.umlib.nl/taverne-license

Take down policy

If you believe that this document breaches copyright please contact us at:

repository@maastrichtuniversity.nl

providing details and we will investigate your claim.
}

Copyright and moral rights for the publications made accessible in the public portal are retained by the authors and/or other copyright owners and it is a condition of accessing publications that users recognise and abide by the legal requirements associated with these

- Users may download and print one copy of any publication from the public portal for the purpose of private study or research.

- You may not further distribute the material or use it for any profit-making activity or commercial gain

If the publication is distributed under the terms of Article $25 \mathrm{fa}$ of the Dutch Copyright Act, indicated by the "Taverne" license above, 


\title{
The Feasibility of High-Resolution Peripheral Quantitative Computed Tomography (HR-pQCT) in Patients with Suspected Scaphoid Fractures
}

\author{
M.S.A.M. Bevers, ${ }^{1}$ A.M. Daniels, ${ }^{2,3}$ C.E. Wyers, ${ }^{3,4,5}$ B. van Rietbergen, ${ }^{1,6}$ \\ P.P.M.M. Geusens, ${ }^{5,7}$ S. Kaarsemaker, ${ }^{8}$ H.M.J. Janzing, ${ }^{2}$ P.F.W. Hannemann, ${ }^{9}$ \\ M. Poeze, ${ }^{3,9}$ and J.P.W. van den Bergh ${ }^{3,4,5,7, *}$
}

${ }^{1}$ Orthopaedic Biomechanics, Department of Biomedical Engineering, Eindhoven University of Technology, Eindhoven, the Netherlands; ${ }^{2}$ Department of Surgery, VieCuri Medical Centre, Venlo, the Netherlands; ${ }^{3}$ NUTRIM School for

Nutrition and Translational Research in Metabolism, Maastricht University, Maastricht, the Netherlands; ${ }^{4}$ Department of Internal Medicine, Subdivision of Endocrinology, VieCuri Medical Centre, Venlo, the Netherlands; ${ }^{5}$ Department of Internal Medicine, Maastricht University Medical Centre, Maastricht, the Netherlands; ${ }^{6}$ Department of Orthopaedic Surgery, Research School CAPHRI, Maastricht University Medical Centre, Maastricht, the Netherlands; ${ }^{7}$ Faculty of Medicine, Hasselt University, Belgium; ${ }^{8}$ Department of Orthopaedic Surgery, VieCuri Medical Centre, Venlo, the Netherlands; and ${ }^{9}$ Department of Surgery and Trauma Surgery, Maastricht University Medical Centre, Maastricht, the Netherlands

\begin{abstract}
Introduction: Diagnosing scaphoid fractures remains challenging. High-resolution peripheral quantitative computed tomography (HR-pQCT) might be a potential imaging technique, but no data are available on its feasibility to scan the scaphoid bone in vivo. Methodology: Patients ( $\geq 18$ years) with a clinically suspected scaphoid fracture received an HR-pQCT scan of the scaphoid bone (three $10.2-\mathrm{mm}$ stacks, $61-\mu \mathrm{m}$ voxel size) with their wrist immobilized with a cast. Scan quality assessment and bone contouring were performed using methods originally developed for HR-pQCT scans of radius and tibia. The contouring algorithm was applied on coarse hand-drawn pre-contours of the scaphoid bone, and the resulting contours (AUTO) were manually corrected (sAUTO) when visually deviating from bone margins. Standard morphologic analyses were performed on the AUTO- and sAUTO-contoured bones. Results: Ninety-one patients were scanned. Two out of the first five scans were repeated due to poor scan quality $(40 \%)$ based on standard quality assessment during scanning, which decreased to three out of the next 86 scans $(3.5 \%)$ when using an additional thumb cast. Nevertheless, after excluding one scan with an incompletely scanned scaphoid bone, post hoc grading revealed a poor quality in $14.9 \%$ of the stacks and $32.9 \%$ of the scans in the remaining 85 patients. After excluding two scans with contouring problems due to scan quality, bone indices obtained by AUTO- and sAUTO-contouring were compared in 83 scans. All AUTO-contours were manually corrected, resulting in significant but small differences in densitometric and trabecular indices $(<1.0 \%)$. Conclusions: In vivo HR-pQCT scanning of the scaphoid bone is feasible in patients with a clinically suspected scaphoid fracture when using a cast with thumb part. The proportion of poor-quality stacks is similar to radius scans, and AUTO-contouring appears appropriate in good- and poor-quality scans . Thus, HR-pQCT may be promising for diagnosis of and microarchitectural evaluations in suspected scaphoid fractures.
\end{abstract}

Received 04/26/19; Revised 08/09/19; Accepted 08/12/19.

*Address correspondence to: J.P.W. van den Bergh, MD, PhD, VieCuri Medical Centre, Department of Internal Medicine, Tegelseweg 2105912 BL Venlo, the Netherlands. E-mail: jvdbergh@viecuri.nl 
Key Words: scaphoid fracture; high-resolution peripheral quantitative computed tomography; in vivo imaging; scan quality; automatic contouring algorithm.

\section{Introduction}

Scaphoid fractures account for approximately $60 \%-75 \%$ of all carpal fractures $(1-4)$ and can have long-term complications when they are not immediately treated. The treatment is usually conservative (i.e. cast) for stable and nondisplaced fractures and operative (e.g. screw fixation) for unstable or displaced fractures (5). A delay in treatment may cause healing complications and increased healing time and an increased risk for a scaphoid nonunion $(6,7)$. A scaphoid nonunion, in turn, is challenging to treat successfully and can cause carpal instability and osteoarthritis (8).

Early diagnosis and adequate treatment of scaphoid fractures is thus important, but immediate diagnosis remains challenging. Plain radiography is typically used at initial presentation, but misses up to $25 \%$ of scaphoid fractures compared to magnetic resonance imaging, computed tomography, and bone scintigraphy (9). While these advanced imaging techniques have a better sensitivity and specificity than radiography $(10,11)$, they lack good positive predictive values, and their improved sensitivity is generally associated with a reduced specificity and vice versa $(12,13)$. Consequently, there is no consensus today on a gold standard imaging technique for scaphoid fractures $(14,15)$.

High-resolution peripheral quantitative CT (HRpQCT) may be a potential alternative imaging technique. It is a noninvasive technique that provides 3-dimensional images of peripheral bones at a low radiation dose and with a spatial resolution higher than currently used imaging techniques (16). Its high resolution may enable recognizing more and smaller scaphoid fractures than currently used techniques and enables microarchitectural bone evaluations of (fractured) scaphoid bones, which have already provided new insights into fracture mechanism, nonunion etiology, and optimal screw fixation and design in cadaveric bones $(17-21)$.

Although the use of HR-pQCT in scaphoid fractures may thus be interesting for diagnostic and research purposes, the feasibility of in vivo HR-pQCT scanning of the scaphoid bone is not yet fully explored. To our knowledge, Reina et al performed the only in vivo HR-pQCT study on the scaphoid bone thus far, investigating the patterns in trabecular bone between normal dominant and nondominant radial carpal bones (22). In that study, nothing was reported about motion artefacts or image quality of the HR-pQCT scans. However, it is unknown whether subject motion is comparable or worse in scaphoid bone scans compared to radius or tibia scans as 3 stacks rather than 1 are needed to capture the entire scaphoid bone (23) and whether image quality is adequate for application in clinical practice. This study, therefore, explored the feasibility of in vivo HR-pQCT scanning of the scaphoid bone in patients with a clinically suspected scaphoid fracture. Scan-quality assessment and scaphoid bone contouring were performed using methods originally developed for HR-pQCT scans of radius and tibia, and differences in bone indices were determined between contours with and without manual correction.

\section{Methodology \\ Study Design and Population}

All consecutive patients (aged $\geq 18 \mathrm{yr}$ ) presenting between December 2017 and October 2018 at the emergency department of VieCuri Medical Centre Venlo (The Netherlands) within 1 wk after trauma with a clinically suspected scaphoid fracture were eligible for study participation. Patients were excluded in case of pregnancy or a previous ipsilateral scaphoid fracture in medical history. All included patients gave written consent prior to participation. The study protocol (METC registration number NL62476.068.17) was approved by an independent Medical Ethics Committee and complied with the Declaration of Helsinki of 1975, revised in 2000.

The included patients followed the standard diagnostic protocol for suspected scaphoid fractures. They were subjected to standard plain radiography at initial presentation followed by immobilization of the wrist with a synthetic nonfiberglass cast. Within $10 \mathrm{~d}$ after initial presentation, a clinical reassessment was performed to determine treatment strategy. In addition to this standard protocol and independent of the outcome of the clinical reassessment, all included patients received an HRpQCT scan.

\section{HR-pQCT Imaging}

HR-pQCT (XtremeCTII, Scanco Medical, Switzerland) scans of the scaphoid bone were performed on a $30.6-\mathrm{mm}$ region of the wrist (3 consecutive $10.2-\mathrm{mm}$ stacks) with the reference line at the longitudinal sagittal ridge between the scaphoid bone and lunate fossa at the articular surface of the distal radius (Fig. 1). During scanning, the wrist was immobilized with a synthetic nonfiberglass cast, and standard motion restraining holders for HR-pQCT scanning were used. Synthetic casts have been found to affect scan quality and bone parameters only marginally (24). Total scan time was $6.0 \mathrm{~min}$, subjecting the patients to an effective radiation dose of approx 15 $\mu \mathrm{Sv}$. X-ray tube voltage and intensity were $68 \mathrm{kV}$ and $1460 \mu \mathrm{A}$, respectively, and integration time was $43 \mathrm{~ms}$. The images were reconstructed using an isotropic voxel size of $61 \mu \mathrm{m}$, resulting in 504 consecutive slices (25). 

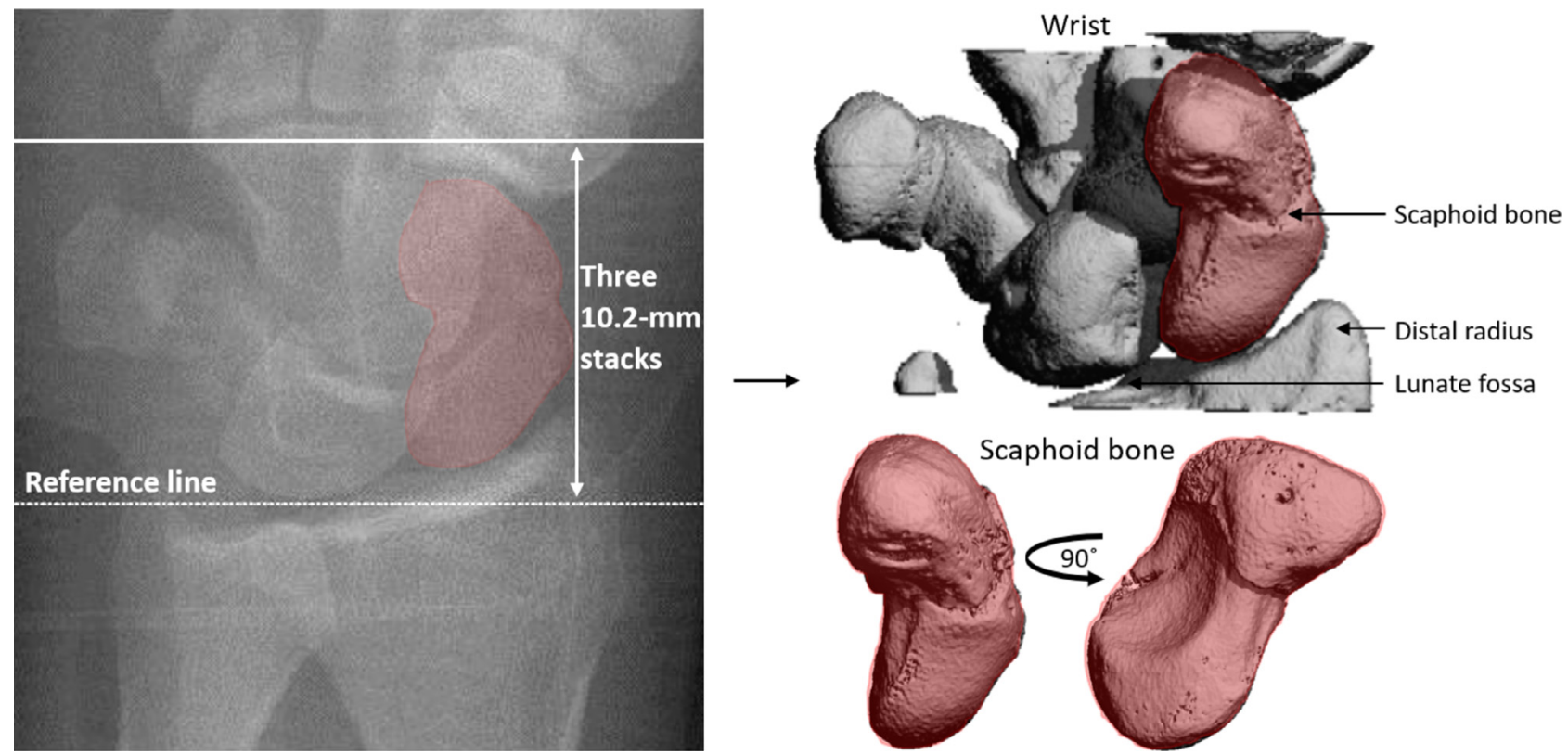

Fig. 1. Scout view showing the reference line used to scan the scaphoid bone (left) and a 3-dimensional view of the scanned region of the wrist (right top) and of the scaphoid bone (right bottom).

\section{Scan-quality Assessment}

Scan quality was graded using the grading system used by Pialat et al to grade HR-pQCT scans of radius and tibia (26). A single low-resolution slice of each stack of the scans was graded by the operator during scan acquisition (standard grading). Scans were completely repeated once when the quality of at least 1 stack had a grade $>3$. The scan with the best quality in the 3 stacks was included for further analyses. Additionally, scan quality was post hoc graded by 1 researcher using the same grading system on multiple full-resolution slices of each stack (post hoc grading). More specifically, the first slice in which the scaphoid bone appeared was determined, and from that slice on every tenth slice was graded. Based on these gradings, an overall grade was determined for each stack. The entire scan was assigned a good quality when each of the 3 stacks had a grade $1-3$ and a poor quality when at least 1 stack had a grade $>3$.

\section{Scaphoid Fracture Assessment}

All HR-pQCT scans were evaluated by an experienced radiologist to assess fractures.

\section{Scaphoid Bone Contouring}

To investigate the quantitative potential of HR-pQCT in scaphoid bones, the scaphoid bones were contoured in the scans. Initially, the automatic contouring algorithm, originally developed to contour radius and tibia and similar to the algorithm for automatic contouring of the periosteal and endosteal margins of radius and tibia (27), was used to contour the scaphoid bone. However, its application on the scaphoid bone scans resulted in severe contouring problems, including contouring the wrong bone (Fig. 2A) and multiple bones (Fig. 2B). Therefore, its application was changed from the entire scan of the scaphoid bone to coarse hand-drawn precontours of the bone. Moreover, the lower threshold for binarization was changed from the default $120-105$ per 1000 as the cortex of the scaphoid bone is thinner and less mineralized than that of radius and tibia. The resulting contouring algorithm (AUTO) thus comprised manual drawing of coarse precontours of the scaphoid bone followed by application of the automatic contouring algorithm with adjusted settings on these coarse contours, which solved the problems of applying the contouring algorithm on entire scans (Fig. 2C-D). As a separate study procedure, the obtained AUTO contours were manually corrected (sAUTO) by 1 researcher when visually deviating from the margins of the scaphoid bone.

\section{Quantitative Analysis}

Standard morphologic analyses were performed on the AUTO- and sAUTO-contoured scaphoid bones. Bone and tissue mineral density (BMD and TMD, respectively) were determined, as were the ratio of bone volume to total bone volume (BV/TV) and trabecular number ( $\mathrm{Tb}$. $\mathrm{N})$, thickness (Tb.Th), and separation (Tb.Sp). The trabecular indices were calculated using distance transformation (28). Cortical indices were not determined because of the lack of a clear cortical layer in the scaphoid bone. 

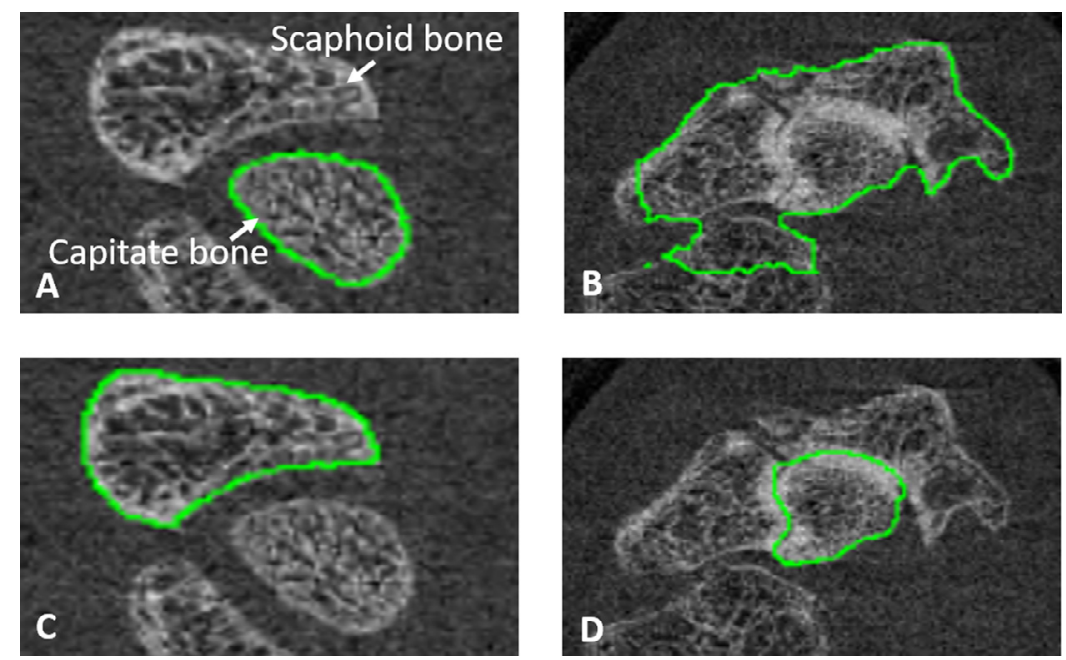

Fig. 2. Problems of the automatic contouring algorithm originally developed for radius and tibia in contouring (A) the correct bone and (B) only 1 bone. These problems were solved when applying the algorithm on coarse hand-drawn precontours of the scaphoid bone $(\mathrm{C}-\mathrm{D})$.

\section{Statistical Analysis}

The quantitative measures obtained were statistically analyzed (IBM SPSS Statistics for Windows, Version 25.0. Armonk, NY: IBM Corp). Normality of the distribution of the data was analyzed using Shapiro-Wilk tests. Differences in patient characteristics between poor-and good-quality scans were analyzed using Mann-Whitney $U$ and chi-square tests and determinants of scan quality using uni- and multivariate binomial logistic regression models with covariates age, gender, and the presence of a scaphoid fracture. Differences in bone indices between the AUTO- and sAUTO-contoured scaphoid bones were analyzed using paired-sample $t$ tests or related-samples Wilcoxon signed rank tests and performed on the entire dataset and on subgroups with either good-quality scans (grade 1-3 for all 3 stacks of a scan), poor-quality scans (grade 4-5 for at least 1 of the 3 stacks), scans with a scaphoid fracture, or scans without a scaphoid fracture. Additionally, the differences in bone indices between both contouring methods were compared between the good- and poor-quality scans and between the scans with and without a scaphoid fracture within the subgroups of poor- and good-quality scans using Mann-Whitney $U$ tests. All tests were 2-sided, and the significance level was set at 0.05 .

\section{Results}

\section{Patient Characteristics}

Ninety-one patients were included in the study, 45 men $(49.5 \%)$ and 46 women with a median age of $37 \pm 32$ and $62 \pm 24 \mathrm{yr}$, respectively. Twenty-four patients $(26.4 \%)$ were diagnosed with a scaphoid fracture (15 men and 9 women) based on the HR-pQCT scans. Median time between initial presentation at the emergency department and HR-pQCT scanning was $9 \mathrm{~d}$ (range: $2-13 \mathrm{~d}$ ).

The scans of 6 patients were excluded from further analyses (Fig. 3A). The scans of the first 5 patients were excluded: the scans of 2 out of these first patients (40\%) had to be repeated due to a poor quality based on the standard grading. In an attempt to reduce this proportion, the next patients received the original cast (Fig. 4A) extended with a temporary thumb part (Fig. 4B). This adaptation lowered the proportion of rescanning due to poor quality to $3.5 \%$ ( 3 out of 86 scans). Only these 86 scans were included in further analyses to keep uniformity in casting procedure among patients. Of these scans, 1 scan was excluded because the scaphoid bone was not entirely scanned due to a wrong positioning of the wrist in the scanner, resulting in a total of 85 included scans (Fig. 3A).

\section{Scan-Quality Assessment}

Based on the standard grading, 4 out of the 85 scans $(4.7 \%)$ were assessed as poor quality, while 28 scans $(32.9 \%)$ were assessed as poor quality based on the post hoc grading (Fig. 3A, Table 1). Although the standard grading assessed scans as poor quality that were also assessed as poor quality during the post hoc grading, it missed 24 poor-quality scans compared to the post hoc grading (Fig. 3A). Patients with poor-quality scans based on the post hoc grading were significantly older than those with good-quality scans (Table 1 ), and logistic regression models showed age to be significantly associated with scan quality in a univariate model $\left(\mathrm{OR}_{10 \mathrm{yrs}}=1.47,95 \%\right.$ $\mathrm{CI}=1.13-1.92)$ and in multivariate models with gender and/or the presence of a scaphoid fracture as other covariates (Supplementary Table 1). More than half of the poor-quality scans had only 1 poor-quality stack $(75.0 \%$ and $64.3 \%$ for standard grading and post hoc grading, 


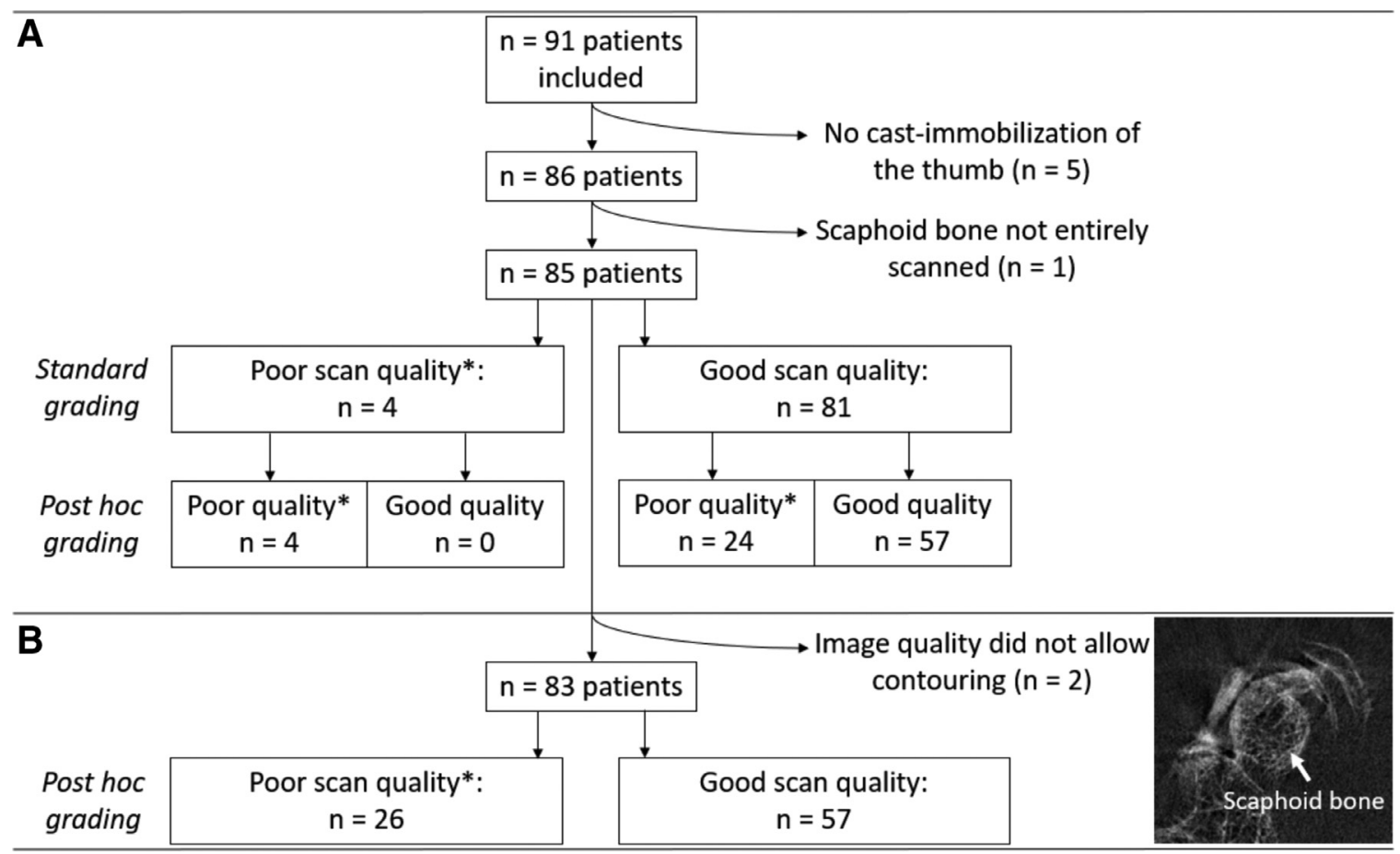

${ }^{*}$ A scan with at least one of the three stacks having a grade $>3$ due to motion artifacts

Fig. 3. Flow-chart of the included scans for (A) the determination of patient characteristics of poor- and good-quality scans based on the standard grading and post hoc grading, and (B) scaphoid bone contouring.

respectively) (Table 1). Stated differently, the post hoc grading revealed 18 of 85 scans $(21.2 \%)$ to have a poor quality in only 1 stack $(21.2 \%)$ and 38 of 255 stacks $(14.9 \%)$ to be of poor quality, which was the middle stack in $50 \%$ of the scans (Table 1). Scans with multiple poorquality stacks had a poor-quality proximal and distal stack in $50 \%$ of the cases (post hoc grading; Table 1).

\section{Scaphoid Bone Contouring}

The scans of 2 patients out of the 85 included scans were excluded from quantitative analyses because their scan quality did not allow contouring (Fig. 3B), resulting in 83 scans.

The AUTO-algorithm solved the problems of the automatic algorithm (Fig. 2), but incorrectly contoured the scaphoid bone in the first and last few slices due to its anatomy, which required manual contour corrections (sAUTO) in all 83 scans (Figs. 5A1 and 2), as well as scaphoid bones with (displaced) fractures (Fig. 5B), small joint spaces due to rheumatoid arthritis or osteoarthritis (Fig. 5C) or thin subchondral bone layers (Fig. 5D) and scaphoid bones in poor-quality scans (Fig. 5E). The sAUTO-contours resulted in significant, but small differences in bone indices (Table 2, Fig. 6A). In the subgroups of good- and poor-quality scans (post hoc grading), all indices were significantly different between the AUTOand sAUTO-contoured scaphoid bones except for Tb.N and $\mathrm{BV} / \mathrm{TV}$, respectively (Table 3 ). Nevertheless, all differences were $<0.5 \%$ (except Tb.Th $<1.0 \%$ ) (Fig. 6A) Percentage differences between both contouring methods were in general larger in the poor-quality scans and reached statistical significance for TMD and the trabecular indices (Fig. 6A). Within the subgroup of poor-quality scans, differences between the AUTO- and sAUTO-contoured bones were in general larger in scans with multiple poor-quality stacks or a poor-quality middle stack than in those with 1 poor-quality stack or a poor-quality proximal or distal stack (Supplementary Fig. 1). In the subgroups of scans with and without a scaphoid fracture, all indices were significantly different between the AUTO- and sAUTO-contoured bones except for Tb.N in the former and BV/TV in the latter subgroup (Table 4). Percentage differences differed significantly between scans with and without a scaphoid fracture for TMD within the subgroup of good-quality scans (post hoc grading), and for BV/TV, $\mathrm{BMD}$, and Tb.N within the subgroup of poor-quality scans (Fig. 5B).

\section{Discussion}

This study showed that in vivo HR-pQCT scanning of the scaphoid bone is feasible in patients with a clinically suspected scaphoid fracture. The proportion of repeated scans considerably improved by extending the wristimmobilizing cast, worn during scanning, with a temporary thumb part. The proportion of post hoc graded poor-quality stacks $(14.9 \%)$ was considerably lower than 


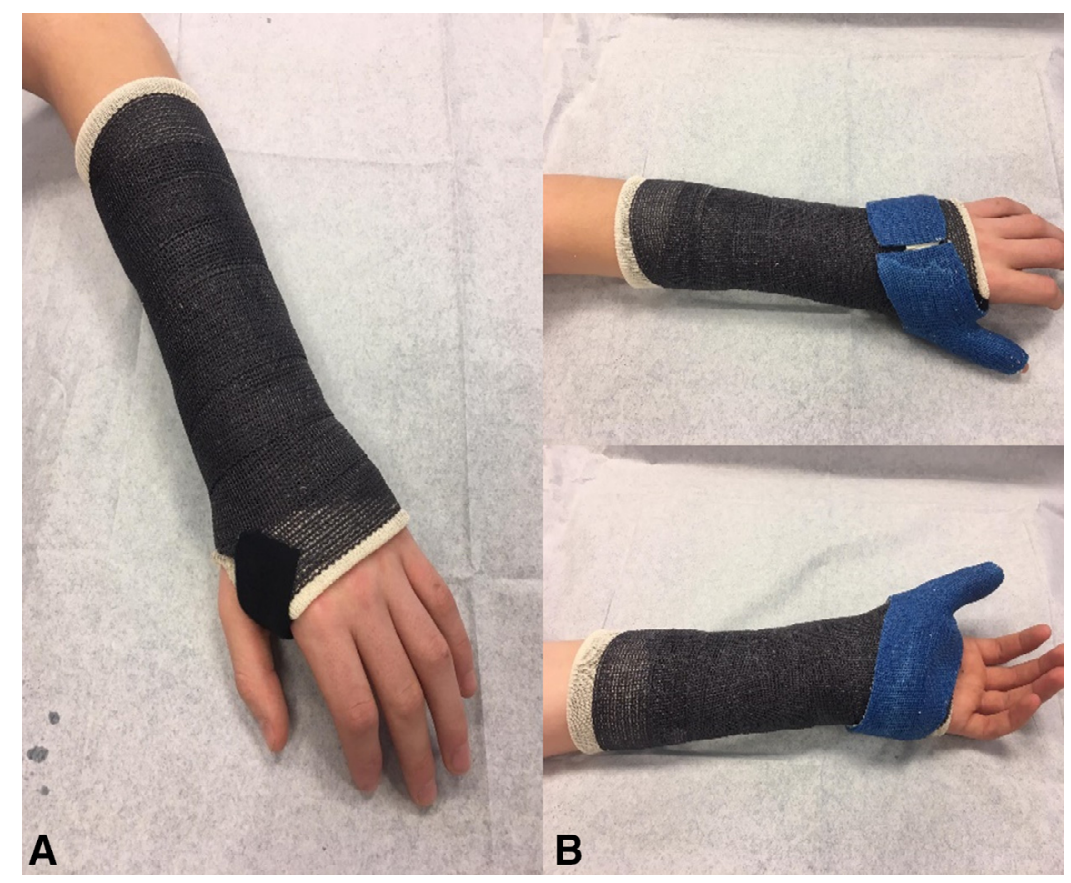

Fig. 4. Synthetic nonfiberglass cast used to immobilize the wrist during scanning. (A) The original cast, and (B) the original cast (black) extended with an removable thumb cast (blue) seen from a dorsal (top) and volar (bottom) perspective. (Color version of figure is available online.)

Table 1

Patient Characteristics According to Scan Quality

\begin{tabular}{|c|c|c|c|c|c|c|}
\hline \multirow[b]{2}{*}{ Characteristic } & \multicolumn{3}{|c|}{ Standard grading } & \multicolumn{3}{|c|}{ Post hoc grading } \\
\hline & $\begin{array}{l}\text { Good quality } \\
\text { (grade } 1-3 \text { ) }\end{array}$ & $\begin{array}{l}\text { Poor quality } \\
\text { (grade }>3)^{*}\end{array}$ & $p$ value & $\begin{array}{l}\text { Good quality } \\
\text { (grade } 1-3 \text { ) }\end{array}$ & $\begin{array}{l}\text { Poor quality } \\
(\text { grade }>3)^{*}\end{array}$ & $p$ value \\
\hline \multicolumn{7}{|l|}{ Number $(\%)$} \\
\hline All $(n=85)$ & $81(95.3)$ & $4(4.7)$ & & $57(67.1)$ & $28(32.9)$ & \\
\hline Scaphoid fracture $(n=21)$ & $21(100.0)$ & $0(0.0)$ & 0.241 & $16(76.2)$ & $5(23.8)$ & 0.305 \\
\hline No scaphoid fracture $(n=64)$ & $60(93.8)$ & $4(6.3)$ & & $41(64.1)$ & $23(35.9)$ & \\
\hline Gender - Male (\%) & $41(50.6)$ & $1(25.0)$ & 0.317 & $29(50.9)$ & $13(46.4)$ & 0.700 \\
\hline Median age \pm IQR (yr) & $52 \pm 38$ & $59.5 \pm 29$ & 0.328 & $47 \pm 37$ & $64.5 \pm 64$ & 0.003 \\
\hline \multicolumn{7}{|l|}{ Quality distribution over stacks } \\
\hline One stack (\%) & - & $3(75.0)$ & & - & $18(64.3)$ & \\
\hline Proximal stack & & $1(33.3)$ & & & $3(16.7)$ & \\
\hline Middle stack & & $0(0.0)$ & & & $9(50.0)$ & \\
\hline Distal stack & & $2(66.7)$ & & & $6(33.3)$ & \\
\hline Two stacks $(\%)$ & - & $1(25.0)$ & & - & $10(35.7)$ & \\
\hline Proximal and middle stack & & $1(100.0)$ & & & $3(30.0)$ & \\
\hline Proximal and distal stack & & $0(0.0)$ & & & $5(50.0)$ & \\
\hline Middle and distal stack & & $0(0.0)$ & & & $2(20.0)$ & \\
\hline Three stacks (\%) & - & $0 * *(0.0)$ & & - & $0 * *(0.0)$ & \\
\hline
\end{tabular}

*A scan was assigned a poor quality if at least 1 of the 3 stacks of a scan had a grade $>3$ due to motion artifacts.

** One scan had a scaphoid bone covering only two stacks that were both of poor quality, but is included in the ' 2 stacks'-group. $p$ values $<0.05$ are shown in bold. 

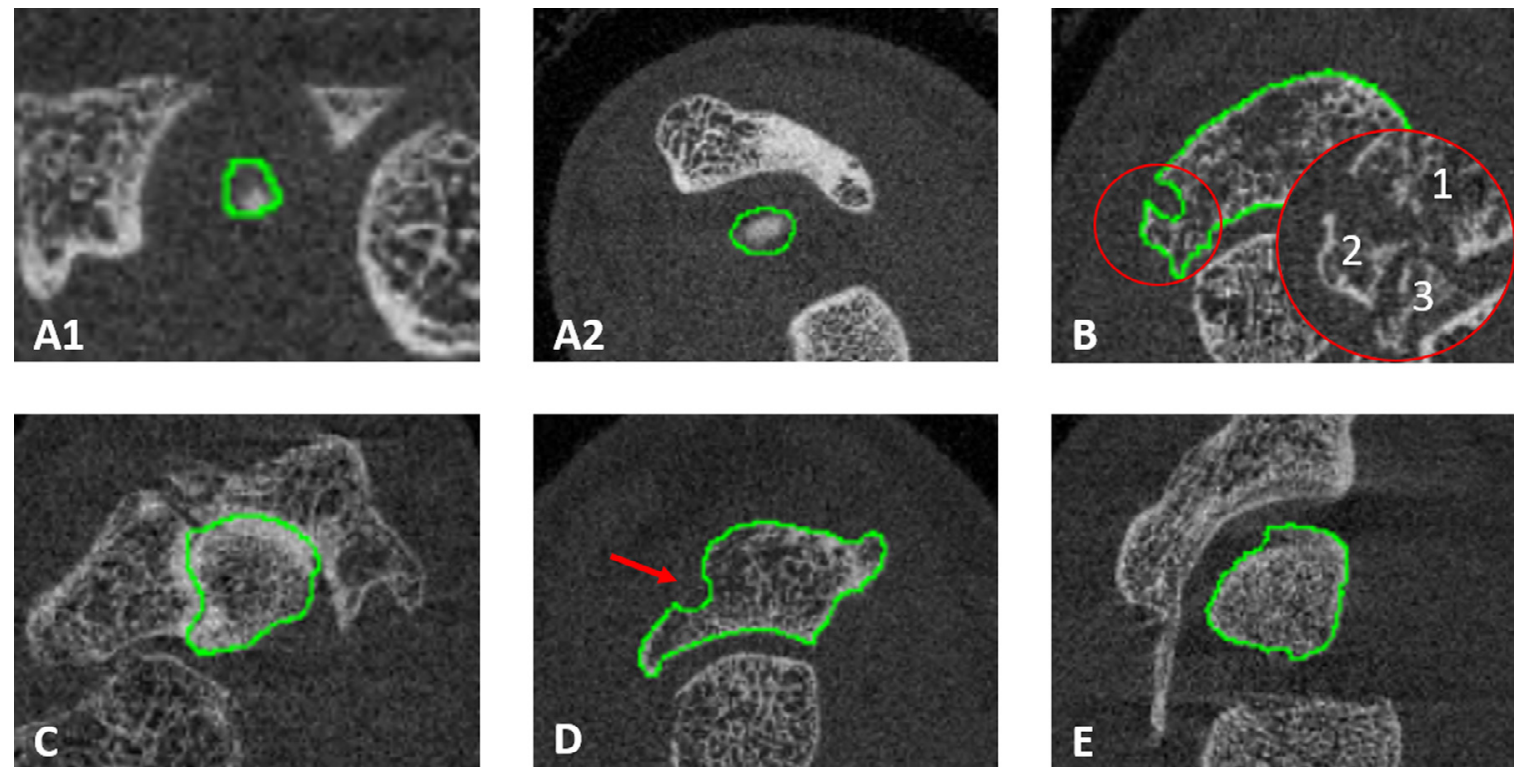

Fig. 5. The automatic contouring algorithm applied on coarse hand-drawn precontours (AUTO) incorrectly contoured the scaphoid bone (A) at the first few (1) and last few (2) slices, and in case of (B) (displaced) fractures, (C) small joint spaces, (D) thin subchondral bone layers, and (E) poor scan quality.

of poor-quality scans $(32.9 \%)$. Manual corrections were needed in the AUTO-contours of all scans, but the resulting differences in bone indices were $<1 \%$ for all bone indices in good- and poor-quality scans and scans with and without a scaphoid fracture.

A wrist- and thumb-immobilizing cast was necessary to reduce motion artifacts. While $40 \%$ of the first 5 scans had to be repeated due to motion artifacts using the original cast based on the standard grading during scan acquisition, extension of this cast with a thumb part lowered this proportion to $3.5 \%$. An additional thumb cast is therefore recommended in future HRpQCT studies scanning patients with a suspected scaphoid fracture.
Despite this adjusted cast, still $32.9 \%$ of the scans were post hoc assessed as poor quality, which is considerably higher than the poor-quality rate in 1-stack radius scans $(3 \%-19 \%)(29-32)$. This relatively large poor-quality rate may have been caused by movement excursions due to the more distal scan region for scaphoid bone scans $(29,31)$, which seemed to be more common in older patients considering the age dependency in scan quality. Also the necessity to scan 3 stacks to capture the entire scaphoid bone rather than 1 stack may explain the relatively large poor-quality rate as the proportion of poorquality stacks $(14.9 \%)$ is in agreement with the poor-quality rates in the radius. This comparable poor-quality stack rate and the recent approved clinical use of HR-pQCT

Table 2

Difference in Densitometric and Trabecular Structural Bone Parameters Between Automatically Contoured Scaphoid Bone (AUTO) and Manually Corrected Contours (sAUTO)

\begin{tabular}{lccrr}
\hline Parameter & AUTO $(n=83)$ & sAUTO $(n=83)$ & Difference & $p$ value \\
\hline Densitometric & & & & \\
BV/TV [\%] & $53.0 \pm 7.85$ & $53.0 \pm 7.92$ & $-0.0400 \pm 0.130$ & $\mathbf{0 . 0 0 4}$ \\
BMD [mg HA/CC] & $375 \pm 59.7$ & $375 \pm 60.2$ & $-0.574 \pm 0.954$ & $\mathbf{0 . 0 0 0}$ \\
TMD [mg HA/CC] & $769 \pm 29.4$ & $770 \pm 29.4$ & $-0.834 \pm 0.859$ & $\mathbf{0 . 0 0 0}$ \\
Trabecular structural & & & & \\
Tb.N [mm ${ }^{-1}$ ] & $1.75 \pm 0.159$ & $1.76 \pm 0.160$ & $-0.00120 \pm 0.00340$ & $\mathbf{0 . 0 0 2}$ \\
Tb.Th [mm] & $0.450 \pm 0.0816$ & $0.448 \pm 0.0811$ & $0.00220 \pm 0.00260$ & $\mathbf{0 . 0 0 0}$ \\
Tb.Sp [mm] & $0.521 \pm 0.0731$ & $0.522 \pm 0.0733$ & $-0.000900 \pm 0.00140$ & $\mathbf{0 . 0 0 0}$ \\
\hline
\end{tabular}

Values are mean \pm SD.

$p$ Values $<0.05$ are shown in bold. 

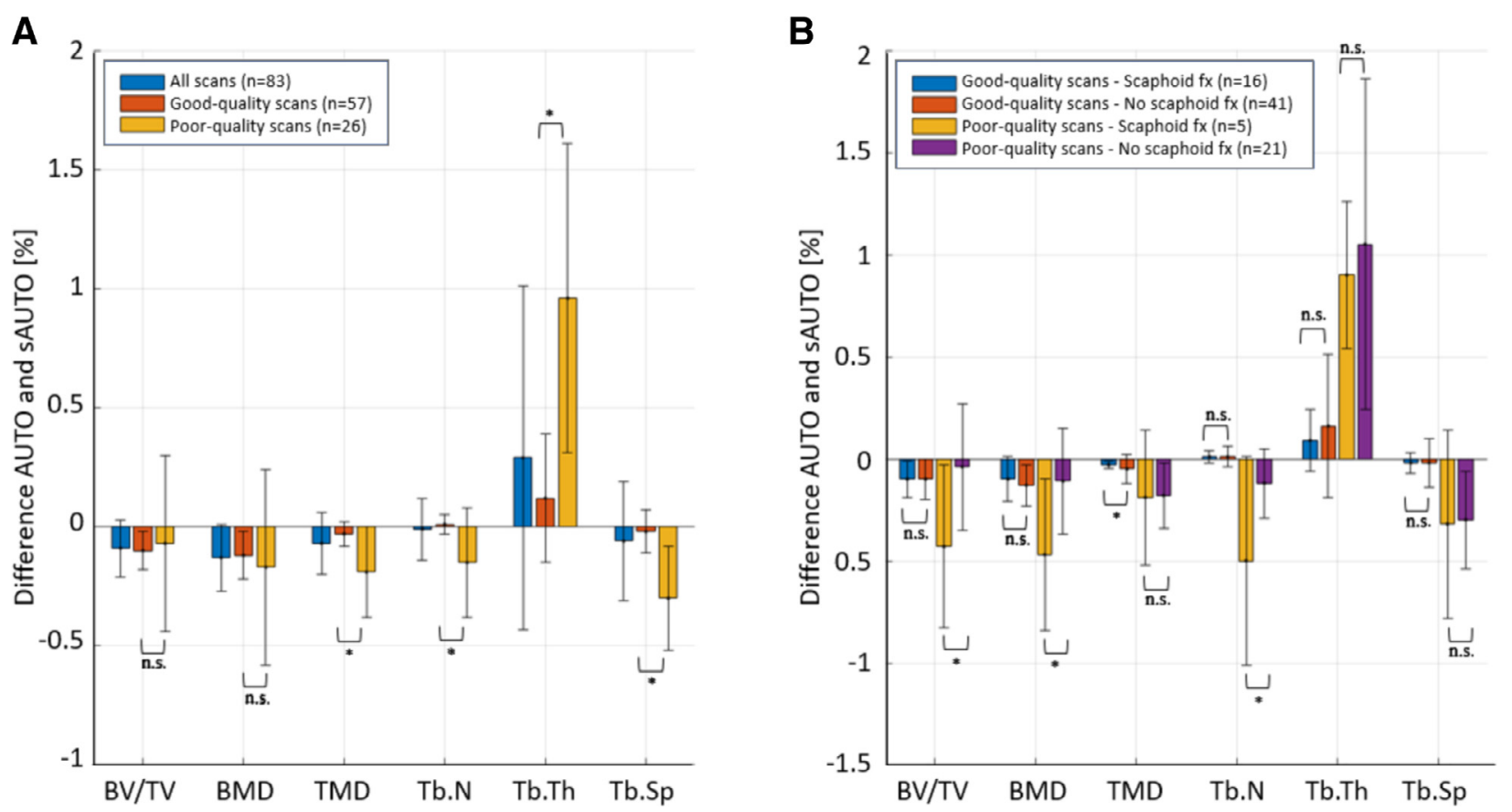

Fig. 6. Median $( \pm I Q R)$ percentage difference in bone indices between the automatically contoured scaphoid bone without (AUTO) and with (sAUTO) manual corrections for A) all scans, good-quality scans, and poor-quality scans and for B) good- and poor-quality scans with and without fractured scaphoid bones. Scan quality is based on post hoc grading, and the significance level is set at 0.05 .

for osteoporosis assessment in adult patients may suggest that the image quality of HR-pQCT is sufficient for diagnosis of scaphoid fractures, but this needs to be further investigated.

Adequate image quality is also required for microarchitectural bone evaluations. Previous studies recommended to repeat or exclude poor-quality radius and tibia scans (i.e. 1-stack scans with grade $>3$ ) because of their influence on bone indices (33), but these recommendations might be different for scaphoid bone scans (i.e. 3 -stack scans). Because bone indices are determined over the entire bone, the relative $\mathrm{BV}$ affected by subject motion likely influences the effect of subject motion on bone indices. This idea is reinforced by our finding that bone indices were more influenced by manual contour corrections in poor-quality scans with multiple poor-quality stacks or a poor-quality middle stack than in scans with 1 poor-quality stack or a poor-quality proximal or distal stack. Possibly, an additional distinction within 3 -stack poor-quality scans based on relative motionaffected BV might reduce the number of scaphoid bone scans that should be repeated or excluded from quantitative analyses, which requires a reproducibility study on the effects of subject motion on bone indices (26).

Microarchitectural evaluations require also proper bone contouring. Applied on coarse hand-drawn precontours, the standard algorithm for automatic radius and tibia contouring appeared to correctly contour the scaphoid bone.
Although manual corrections were necessary in all scans, they caused differences in bone indices $(<0.5 \%$, except $\mathrm{Tb}$.Th $<1.0 \%$ ) smaller than the voxel size of the scans and smaller than longitudinal bone changes in radius and tibia due to ageing, treatment, or repeated scans $(26,32,34,35)$. It is thus questionable whether manual corrections are needed, especially when taking into account time consumption (5-15 min for good-quality scans and 30-60 min for poor-quality scans) and expected interobserver variability and reduced reproducibility (36). The ability to automatically contour the scaphoid bone on HR-pQCT scans allows for microarchitectural bone evaluations in suspected scaphoid fractures and possibly also for research into the healing process of these fractures (32).

Although this study was the first to explore the feasibility of in vivo HR-pQCT scanning of the scaphoid bone and used a uniform protocol and cast for every patient to allow between-patient comparison (24), it had several limitations. First, only 1 researcher post hoc graded scan quality and manually corrected contours, whereas both are known to be subjective in radius and tibia scans $(26,36)$. The subjectivity in grading may be even larger in scaphoid bone scans considering the discrepancy between standard and post hoc grading of $85.7 \%$ (i.e. the standard grading missed $85.7 \%$ of the scans that were post hoc assessed as poor quality), which is considerably higher than the $12 \%$ reported in literature on 1 -stack radius and tibia scans (i.e. theoretically $36 \%$ in 3 -stack scans) (26). 
Table 3

Difference in Densitometric and Trabecular Structural Bone Parameters Between Automatically Contoured Scaphoid Bone (AUTO) and Manually Corrected Contours (sAUTO) for the Subgroups of Good- and Poor-Quality Scans Based on post hoc Grading.

\begin{tabular}{|c|c|c|c|c|c|c|c|c|}
\hline \multirow[b]{2}{*}{ Parameter } & \multicolumn{4}{|c|}{ Good quality (grade $1-3 ; n=57$ ) } & \multicolumn{4}{|c|}{ Poor quality (grade $>3 ; n=26$ )* } \\
\hline & AUTO & sAUTO & Difference & $p$ value & AUTO & sAUTO & Difference & $p$ value \\
\hline \multicolumn{9}{|l|}{ Densitometric } \\
\hline $\mathrm{BV} / \mathrm{TV}[\%]$ & $53.5 \pm 7.81$ & $53.6 \pm 7.84$ & $-0.0400 \pm 0.0700$ & 0.000 & $51.7 \pm 7.93$ & $51.8 \pm 8.10$ & $-0.0400 \pm 0.220$ & 0.304 \\
\hline $\mathrm{BMD}[\mathrm{mg} \mathrm{HA} / \mathrm{CC}]$ & $381 \pm 61.4$ & $381 \pm 61.7$ & $-0.464 \pm 0.517$ & 0.000 & $362 \pm 54.9$ & $363 \pm 56.1$ & $-0.813 \pm 1.52$ & 0.011 \\
\hline TMD [mg HA/CC] & $774 \pm 30.7$ & $775 \pm 30.8$ & $-0.447 \pm 0.435$ & 0.000 & $757 \pm 22.5$ & $758 \pm 22.6$ & $-1.68 \pm 0.949$ & 0.000 \\
\hline \multicolumn{9}{|l|}{ Trabecular structural } \\
\hline Tb.N $\left[\mathrm{mm}^{-1}\right]$ & $1.73 \pm 0.148$ & $1.73 \pm 0.148$ & $-0.000200 \pm 0.00200$ & 0.516 & $1.81 \pm 0.168$ & $1.82 \pm 0.172$ & $-0.00340 \pm 0.00470$ & 0.001 \\
\hline Tb.Th $[\mathrm{mm}]$ & $0.450 \pm 0.0886$ & $0.449 \pm 0.0881$ & $0.00110 \pm 0.00140$ & 0.000 & $0.451 \pm 0.0651$ & $0.446 \pm 0.0648$ & $0.00470 \pm 0.00270$ & 0.000 \\
\hline Tb.Sp [mm] & $0.526 \pm 0.0690$ & $0.526 \pm 0.0692$ & $-0.000500 \pm 0.00120$ & 0.003 & $0.511 \pm 0.0818$ & $0.513 \pm 0.0825$ & $-0.00180 \pm 0.00150$ & 0.000 \\
\hline
\end{tabular}

*A scan was assigned a poor quality if at least 1 of the three stacks of a scan had a grade $>3$ due to motion artifacts.

Values are mean \pm SD.

$p$ values $<0.05$ are shown in bold.

Table 4

Difference in Densitometric and Structural Bone Parameters Between Automatically Contoured Scaphoid Bone (AUTO) and Manually Corrected Contours (sAUTO) for the Subgroups of Scans with and Without a Scaphoid Fracture Based on the HR-pQCT Scans.

\begin{tabular}{|c|c|c|c|c|c|c|c|c|}
\hline \multirow[b]{2}{*}{ Parameter } & \multicolumn{4}{|c|}{ Scans with scaphoid fracture $(n=21)$} & \multicolumn{4}{|c|}{ Scans without scaphoid fracture $(n=62)$} \\
\hline & AUTO & sAUTO & Difference & $p$ value & AUTO & sAUTO & Difference & $p$ value \\
\hline \multicolumn{9}{|l|}{ Densitometric } \\
\hline $\mathrm{BV} / \mathrm{TV}[\%]$ & $56.0 \pm 6.03$ & $56.1 \pm 6.12$ & $-0.0900 \pm 0.130$ & 0.004 & $51.9 \pm 8.17$ & $52.0 \pm 8.23$ & $-0.0300 \pm 0.130$ & 0.113 \\
\hline $\mathrm{BMD}[\mathrm{mg} \mathrm{HA} / \mathrm{CC}]$ & $395 \pm 39.9$ & $396 \pm 40.5$ & $-0.825 \pm 1.09$ & 0.002 & $368 \pm 63.9$ & $369 \pm 64.4$ & $-0.489 \pm 0.899$ & 0.000 \\
\hline TMD [mg HA/CC] & $762 \pm 31.6$ & $763 \pm 31.4$ & $-0.562 \pm 0.833$ & 0.006 & $771 \pm 28.6$ & $772 \pm 28.5$ & $-0.926 \pm 0.854$ & 0.000 \\
\hline \multicolumn{9}{|l|}{ Structural } \\
\hline Tb.N $\left[\mathrm{mm}^{-1}\right]$ & $1.80 \pm 0.186$ & $1.81 \pm 0.189$ & $-0.00190 \pm 0.00490$ & 0.086 & $1.74 \pm 0.146$ & $1.74 \pm 0.147$ & $-0.000900 \pm 0.00270$ & 0.011 \\
\hline Tb.Th $[\mathrm{mm}]$ & $0.458 \pm 0.0628$ & $0.457 \pm 0.0619$ & $0.00150 \pm 0.00200$ & 0.003 & $0.447 \pm 0.0873$ & $0.445 \pm 0.0869$ & $0.00250 \pm 0.00270$ & 0.000 \\
\hline $\mathrm{Tb} . \mathrm{Sp}[\mathrm{mm}]$ & $0.495 \pm 0.0832$ & $0.495 \pm 0.0830$ & $-0.000600 \pm 0.00110$ & 0.032 & $0.530 \pm 0.0677$ & $0.531 \pm 0.0681$ & $-0.00100 \pm 0.00150$ & 0.000 \\
\hline
\end{tabular}

Values are mean $\pm \mathrm{SD}$

$p$ Values $<0.05$ are shown in bold. 
Our large discrepancy may possibly be caused by difficulties in applying the existing quality-grading criteria on scaphoid bone scans as 1 criterium is based on the continuity of the cortical layer, which is extremely thin in the scaphoid bone and which has small interruptions that could reflect transcortical vascular entries rather than cortical discontinuities due to motion artifacts (37). Further research should therefore investigate inter- and intraobserver variability in grading and manually correcting contours and address the applicability of existing grading systems to scaphoid bone scans. Second, in this study the newest second-generation HR-pQCT scanner was used, whereas many first-generation systems are still in use. The use of the first-generation scanner would have likely resulted in a larger proportion of poor-quality scans because of a longer scanning time ( $8.4 \mathrm{~min}$ for a $27.1-\mathrm{mm}$ scan using the first-generation $82 \mu \mathrm{m}$-resolution scanner and $6.0 \mathrm{~min}$ for a $30.6-\mathrm{mm}$ scan using the second-generation $61 \mu \mathrm{m}$-resolution scanner (25)). The ability to automatically contour the scaphoid bone, on the other hand, would likely not have been different. Third, stack shifts were observed in the scans of some patients. Although these shifts could have influenced bone indices, they were not accounted for in the analyses because of their expected limited effect on bone indices. Fourth, although the comparable poor-quality stack rate and the recent approved clinical use of HR-pQCT for osteoporosis assessment in adult patients indicates that the image quality of HR-pQCT may be sufficient for diagnosis of scaphoid fractures, its diagnostic performance for scaphoid fractures is currently not known, and it has to be further studied what quality of HR-pQCT scans is needed for adequate diagnosis of these fractures. Fifth, gender was not taken into account in the analyses despite the epidemiological differences between men and women with a fractured scaphoid bone.

In conclusion, in vivo HR-pQCT scanning of the scaphoid bone is feasible in patients with a clinically suspected scaphoid fracture when using a cast with thumb part during scanning. The proportion of poor-quality stacks is similar to radius and tibia scans, and automatic contouring starting from coarse hand-drawn precontours is appropriate. HR-pQCT may be promising for diagnosis of scaphoid fractures, for microarchitectural bone evaluations in patients with a suspected scaphoid fracture, and possibly also for research into the healing process of scaphoid fractures.

\section{Supplementary materials}

Supplementary material associated with this article can be found in the online version at doi:10.1016/j.jocd.2019.08.003.

\section{References}

1. Hove LM. 1999 Epidemiology of scaphoid fractures in Bergen, Norway. Scand J Plast Reconstr Surg Hand Surg 33:423-426.
2. Dennis HHW, Sze ACK, Murphy D. 2011 Prevalence of carpal fracture in Singapore. J Hand Surg 36:278-283.

3. Van Onselen EBH, Karim RB, Hage JJ, Ritt MJPF. 2003 Prevalence and distribution of hand fractures. J Hand Surg 28:491-495.

4. Holloway KL, Moloney DJ, Brennan-Olsen SL, et al. 2015 Carpal and scaphoid fracture incidence in south-eastern Australia: an epidemiologic study. Arch Osteoporos 10:10.

5. Arsalan-Werner A, Sauerbier M, Mehling IM. 2016 Current concepts for the treatment of acute scaphoid fractures. Eur J Trauma Emerg Surg 42:3-10.

6. Eddeland A, Eiken O, Hellgren E, Ohlsson N-M. 1975 Fractures of the scaphoid. Scand J Plast Reconstr Surg 9:234-239.

7. Langhoff O, Andersen JL. 1988 Consequences of late immobilization of scaphoid fractures. J Hand Surg 13:77-79.

8. Mack GR, Bosse MJ, Gelberman RH, Yu E. 1984 The natural history of scaphoid non-union. J Bone Joint Surg Am 66:504-509.

9. Brooks S, Wluka AE, Stuckey S, Cicuttini F. 2005 The management of scaphoid fractures. J Sci Med Sport 8:181-189.

10. Carpenter CR, Pines JM, Schuur JD, et al. 2014 Adult scaphoid fracture. Acad Emerg Med 21:101-121.

11. Yin Z-G, Zhang J-B, Kan S-L, Wang X-G. 2012 Diagnostic accuracy of imaging modalities for suspected scaphoid fractures. J Bone Joint Surg 94-B:1077-1085 British volume.

12. Groves AM, Cheow HK, Balan KK, et al. 200516 detector multislice CT versus skeletal scintigraphy in the diagnosis of wrist fractures: value of quantification of 99Tcm-MDP uptake. Br J Radiol 78:791-795.

13. Mallee W, Doornberg JN, Ring D, et al. 2011 Comparison of CT and MRI for diagnosis of suspected scaphoid fractures. JBJS 93:20.

14. Groves AM, Kayani I, Syed R, et al. 2006 An international survey of hospital practice in the imaging of acute scaphoid trauma. Am J Roentgenol 187:1453-1456.

15. Smith JE, House RH, Gallagher J, Phillips A. 2016 The management of suspected scaphoid fractures in English hospitals: a national survey. Eur J Emerg Med 23:190.

16. Burghardt AJ, Krug R, Majumdar S. 2018 Chapter 55 - highresolution imaging techniques for bone quality assessment. In: Vitamin D; 2018. p. Feldman D, ed. 4th ed, 1007-1041.

17. Su-Bum AL, Hyo-Jin BK, Jae-Myeung CC, et al. 2012 Osseous microarchitecture of the scaphoid: cadaveric study of regional variations and clinical implications. Clin Anat 25:203-211.

18. Qu G, von Schroeder HP. 2008 Trabecular microstructure at the human scaphoid nonunion. J Hand Surg 33:650-655.

19. Leventhal EL, Wolfe SW, Walsh EF, Crisco JJ. 2009 A computational approach to the "optimal" screw axis location and orientation in the scaphoid bone. J Hand Surg 34:677-684.

20. Varga P, Schefzig P, Unger E, et al. 2013 Finite element based estimation of contact areas and pressures of the human scaphoid in various functional positions of the hand. J Biomech 46:984-990.

21. Varga P, Zysset PK, Schefzig P, et al. 2016 A finite element analysis of two novel screw designs for scaphoid waist fractures. Med Eng Phys 38:131-139.

22. Reina N, Cavaignac E, Trousdale WH, et al. 2017 Laterality and grip strength influence hand bone micro-architecture in modern humans, an HRpQCT study. J Anat 230:796-804.

23. Pichler W, Windisch G, Schaffler G, et al. 2010 Computerassisted 3-dimensional anthropometry of the scaphoid. Orthopedics 33. 
24. de Jong JJA, Arts JJ, Meyer U, et al. 2016 Effect of a cast on short-term reproducibility and bone parameters obtained from HR-pQCT measurements at the distal end of the radius. J Bone Joint Surg 98:356-362 American volume.

25. Vilayphiou N, Hämmerle S, Koller B. 2013 The 2nd generation of HR-pQCT: progresses in bone microstructure assessment with 61 um voxel size in vivo scans. J Bone Miner Res: 28.

26. Pialat J, Burghardt AJ, Sode M, et al. 2012 Visual grading of motion induced image degradation in high resolution peripheral computed tomography: impact of image quality on measures of bone density and micro-architecture. Bone 50:111-118.

27. Burghardt AJ, Buie HR, Laib A, et al. 2010 Reproducibility of direct quantitative measures of cortical bone micro-architecture of the distal radius and Tibia by HR-pQCT. Bone 47:519-528.

28. Hildebrand T, Rüegsegger P. 1997 A new method for the model-independent assessment of thickness in three-dimensional images. J Microsc 185:67-75.

29. Macdonald HM, Nishiyama KK, Kang J, et al. 2011 Agerelated patterns of trabecular and cortical bone loss differ between sexes and skeletal sites: a population-based HRpQCT study. J Bone Miner Res 26:50-62.

30. Dalzell N, Kaptoge S, Morris N, et al. 2009 Bone microarchitecture and determinants of strength in the radius and tibia: age-related changes in a population-based study of normal adults measured with high-resolution pQCT. Osteoporos Int 20:1683-1694.

31. Engelke K, Stampa B, Timm W, et al. 2012 Short-term in vivo precision of BMD and parameters of trabecular archi- tecture at the distal forearm and tibia. Osteoporos Int 23:2151-2158.

32. de Jong JJA, Willems PC, Arts JJ, et al. 2014 Assessment of the healing process in distal radius fractures by high resolution peripheral quantitative computed tomography. Bone 64:65-74.

33. Pauchard Y, Liphardt A-M, Macdonald HM, et al. 2012 Quality control for bone quality parameters affected by subject motion in high-resolution peripheral quantitative computed tomography. Bone 50:1304-1310.

34. Gabel L, Macdonald HM, McKay HA. 2017 Sex differences and growth-related adaptations in bone microarchitecture, geometry, density, and strength from childhood to early adulthood: a mixed longitudinal HR-pQCT Study. J Bone Miner Res 32:250-263.

35. Khosla S, Riggs BL, Atkinson EJ, et al. 2006 Effects of sex and age on bone microstructure at the ultradistal radius: a population-based noninvasive in vivo assessment. J Bone Miner Res 21:124-131.

36. de Waard EAC, Sarodnik C, Pennings A, et al. 2018 Reliability of HR-pQCT derived cortical bone structural parameters when using uncorrected instead of corrected automatically generated endocortical contours in a crosssectional study: the Maastricht Study. Calcif Tissue Int 103:252-265.

37. van Alphen NA, Morsy M, Laungani AT, et al. 2016 A three-dimensional micro-computed tomographic study of the intraosseous lunate vasculature: implications for surgical intervention and the development of avascular necrosis. Plast Reconstr Surg 138:869e. 